\title{
Correction to: Usage-Based Transmission Cost Allocation to Wheeling Transactions in Bilateral Markets
}

\author{
M. S. G. Smitha ${ }^{1}$ (D) P. V. Satyaramesh ${ }^{2} \cdot$ P. Sujatha ${ }^{1}$
}

Published online: 13 November 2018

(C) The Institution of Engineers (India) 2018

\section{Correction to: J. Inst. Eng. India Ser. B} https://doi.org/10.1007/s40031-018-0354-4

The original version of this article unfortunately contained a mistake in the second author name. The author name should be P. V. Satyaramesh. The original article has been corrected.

1 Department of Electrical and Electronics Engineering, Jawaharlal Nehru Technological University Ananthapur, Ananthapuramu, Andhra Pradesh 515002, India

2 Vidyut Soudha, Gunadala, Vijayawada, Andhra Pradesh 520004, India 